\title{
Earthworm, an in Vivo System to Screen Proliferative and Antimitotic Compounds
}

\author{
Kamaraj Rajamanikkam, Chandran Rajesh, Ramesh Prakash, Narayanan Selvapalam, \\ Karuppaiah Palanichelvam
}

\begin{abstract}
Amputated earthworm, Eudrilus eugeniae, possessing clitellum region has regenerating ability and develop into complete worms. Earthworm regeneration assay was developed based on this phenomenon and utilized to identify the presence of antimitotic compounds from the rhizomes of medicinal plant Acorus calamus. In continuation of that study, rhizomes of A. calamus was extracted with water and crude residue was obtained after evaporation. Subsequently, to separate the compounds from crude residue it was extracted with five different organic solvents individually such as benzene, chloroform, ethyl acetate, ethanol and methanol. All five different fractions were examined on earthworm regeneration assay to identify its antimitotic potential. Fractions extracted with benzene and chloroform did not inhibit regeneration as blastema was observed. In contrast fractions extracted with methanol and ethyl acetate inhibited the development of blastema. It suggests that methanol and ethyl acetate fractions might possess antimitotic compounds. TLC analysis with ethyl acetate fraction revealed two distinct bands. Compounds eluted from TLC plates decreased mitotic index of Allium cepa root tips and supporting the presence of antimitotic compounds. Surprisingly, fractions extracted with ethanol increased the regeneration capacity of the worms. Our results demonstrate that rhizomes of Acorus calamus possess both antimitotic and proliferative compounds. Hence we suggest that earthworms could be used as an in vivo system to screen both proliferative and antimitotic compounds from unknown sources.
\end{abstract}

Keywords- Eudrilus eugeniae, Acorus calamus, earthworm, antimitotic, proliferative, aqueous extract

\section{INTRODUCTION}

Me edicinal plants are one of the major sources of active ingredients in pharmaceutical products throughout world [1]. Pharmacologically active plant-derived natural products provide leads to the development of new drugs [2]. Angiosperms are known for their scope in providing clinically valuable compounds to treat cancerous growth [3], [4]. Plants have also been source of antimitotic compounds,

Revised Manuscript Received on December 15, 2019.

*Karuppaiah Palanichelvam, Department of Biotechnology Kalasalingam Academy of Research and Education Krishnan Kovil, India. Email: palanichelvam@klu.ac.in

Kamaraj Rajamanikkam, Department of Biotechnology Kalasalingam Academy of Research and Education Krishnan Kovil, India. Email: rajamanikkam94@gmail.com

Chandran Rajesh, Department of Biotechnology Kalasalingam Academy of Research and Education Krishnan Kovil, India. Email: rajesh.c@klu.ac.in

Ramesh Prakash, Department of Chemistry Kalasalingam Academy of Research and Education Krishnan Kovil, India. Email: pkschem07@gmail.com

Narayanan Selvapalam, Department of Chemistry Kalasalingam Academy of Research and Education Krishnan Kovil, India. Email: n.selvapalam@klu.ac.in

which have great potential to treat cancerous growth [5]. Screening of anticancerous or antimitotic compounds from natural resources is necessary to find new leads or effective drug molecules [6].

Many plants, cell culture or animal-based methods have been in practice to screen or validate the active compounds from natural products [7], [8], [9]. Cell proliferation assays such as dye exclusion methods, ATP assay, clonogenic cell survival assay and other methods using cell cultures are in use [10]. Well established in vivo systems to study compounds that induce proliferation are rare.

Many animals have the ability to regenerate new cells or tissues through cell proliferation [11]. However, earthworms have been recently suggested as one of the simple model systems to study regeneration of new tissues [12]. Earthworm species Eudrilus eugeniae, Eisenia fetida, Lumbricus terrestris and Allolobophora chlorotica have been reported to regenerate brains as well [13]. E. eugeniae is a segmented worm and has good regeneration ability when it possesses clitellum region. We have recently reported that regeneration ability of this worm can be used to validate antimitotic compounds from plant extracts [9]. Single medicinal plant may possess many different pharmacologically significant compounds. Acorus calamus plant is reported to have various compounds and is useful to treat cancer, arthritis, inflammatory diseases, diarrhea, dyspepsia, skin disorders, sinusitis, respiratory problems, fevers, bronchitis and other disorders [14]. Bioactive compounds can be separated either by sequential or differential extraction methods either with organic solvents or water. In this study we have used differential extraction method to separate compounds with antimitotic activity from proliferative activity in A. calamus. Different fractions partitioned from aqueous extract of $A$. calamus rhizomes have been tested on amputated earthworms. We report here that earthworm regeneration could be used to identify not only compounds with antimitotic property but also with potential in cell proliferation by using the medicinal plant.

\section{MATERIALS AND METHOD}

\section{A. Plant materials \& Chemicals}

The rhizomes of A. calamus $\mathrm{L}$. and bulbs of Allium cepa $\mathrm{L}$. were purchased and authenticated as described earlier [9]. All chemicals and solvents were purchased in analytical grade from HiMedia or Merck Ltd., India. 


\section{Earthworm, an in Vivo System to Screen Proliferative and Antimitotic Compounds}

\section{B. Preparation of rhizome extract}

Rhizomes of A. calamus were washed thoroughly, air dried, and powdered. Powdered sample [1g] was extracted in $10 \mathrm{~mL}$ of sterile distilled water and kept overnight in a shaker at $30^{\circ} \mathrm{C}$. Aqueous extracted samples were filtered by using Whatman No. 1 filter paper and followed by $0.2-\mu \mathrm{m}$ filter. Water was evaporated to dryness using a rotary evaporator at room temperature. The resultant residue stored in an air-tight container at $4{ }^{\circ} \mathrm{C}$ until further use. The crude aqueous extract residue was differentially partitioned with five different solvents such as benzene, chloroform, ethyl acetate, methanol and ethanol. One ml of organic solvent was used for every $0.1 \mathrm{~g}$ of crude residue obtained from aqueous extract. Subsequently, organic solvents were removed in fume hood. The residues obtained were again dissolved in sterile distilled water and tested with earthworm regeneration assay.

\section{Culture and maintenance of earthworm}

Adult earthworms, E. eugeniae, were collected from the Agricultural Support Centre, Tamil Nadu Agricultural University, Tirunelveli, Tamil Nadu, India. It was maintained in a plastic tub containing soil, cow dung, and leaf litter in appropriate moisture conditions.

Earthworm regeneration assay with amputated worms were followed as described earlier [9]. It was used to check the antimitotic potential of a known or unknown compound. Briefly, healthy adult worms were selected and amputated with a sterile scalpel blade on the $30^{\text {th }}$ segment from the mouth. Amputated worms retain the anterior parts of the body including the clitellum region were kept in separate beds and monitored every $24 \mathrm{~h}$, for the growth of the blastema. Earthworms were injected between the clitellum and the amputation region with $10 \mu \mathrm{L}$ of distilled water or other extract. Injections were performed at 24-h intervals for 8 consecutive days. Five worms were used for each treatment and all experiments were performed at least 3 times.

\section{E. Thin Layer Chromatography}

Crude residue obtained from aqueous extract of rhizomes was extracted with ethyl acetate. For every $1 \mathrm{~g}$ of dried sample, $10 \mathrm{ml}$ ethyl acetate was used for extraction. Aliquot of $10 \mu \mathrm{l}$ was loaded in precoated TLC plate and the sample was resolved by the solvent, petroleum ether. TLC plate was stained with iodine vapors and $\mathrm{Rf}$ values were calculated.

\section{F. Allium cepa root tip assay}

Onion bulbs with newly germinated roots were incubated for 16 hours with distilled water or compounds eluted from TLC plates. Onion bulbs treated with distilled water were used as the control. Following the incubation period, root tips were fixed with ethanol and acetic acid and subsequently treated with $1 \mathrm{~N}$ hydrochloric acid. Root tips were washed and stained with $0.5 \%$ safranin stain $(\mathrm{W} / \mathrm{V})$ before observing under a light microscope. Chromosome morphology and mitotic stages were observed to calculate mitotic index. The mitotic index was calculated as indicated earlier [9].

\section{G. Statistical analysis}

Statistical analysis was performed (mean, standard deviation, and standard error) with unpaired Student's t-test

\section{Earthworm regeneration assay}

in the software tool GraphPad Prism 6.0. P $<0.05$ was considered statistically significant.

\section{RESULTS AND DISCUSSION}

Phytochemical analysis of A. calamus has been mostly done with organic solvents and many compounds reported are hydrophobic (Table 1). Asarones are major compounds identified in rhizomes and leaves of this plant. Phytochemical studies showed that asarones of A. calamus are lipophilic compounds [15]. Asarones have been shown to possess activity to treat pain, inflammation and tumor [16]. We are interested in identifying hydrophilic compounds from this rhizome and hence water was initially used to extract the compounds. We have recently shown that aqueous extract of A. calamus possesses antimitotic activity by using earthworm regeneration ability [9]. Aqueous extract of rhizomes of $A$. calamus would possess many compounds. The dried powder obtained from aqueous extract was differentially fractionated with five different solvents such as benzene, chloroform, ethyl acetate, methanol and ethanol. Organic solvents were evaporated following the extraction and dissolved again in water before injection into worms.

Fractions partitioned from aqueous extract were examined on regeneration of tissues in amputated earthworms as described earlier [9]. Samples of sterile distilled water (control) or fractions extracted were injected once every 24 hours for a period of 8 days and monitored for development of blastema. Wounds in amputated region of all the worms were healed within 24 hours. Initiation of blastema from the amputated region was observed from $3^{\text {rd }}$ day in control worms and developed well after 8 days (Fig 1A). Development of blastema was found in worms injected with fractions partitioned from benzene, ethanol and chloroform (Fig 1C, D and E). It suggests that these three fractions may not have compounds with antimitotic property. Regeneration from amputated region was not detected in worms injected with fractions partitioned from methanol and ethyl acetate, until 8 days from amputation (Fig $1 \mathrm{~B}$ and F). It suggests that these two fractions may possess the compounds that arrest cell division. Surprisingly, the fraction isolated using ethanol induced the regeneration from wounded region much better than controls. It indicates that ethanol fraction may have compounds that promote cell division or other factors that are necessary for growth of new cells.

Although fractions partitioned from ethyl acetate and methanol inhibited blastema development, lethality of worms were approximately 50\% when methanol extracted samples were tested. Methanol fractions might have had compounds that were cytotoxic and hence it was not analyzed further Ethyl acetate and ethanol fractions were injected into 
Table-I: Phytochemicals in A. calamus

\begin{tabular}{|c|l|l|l|}
\hline $\begin{array}{c}\text { S.n } \\
\mathbf{o}\end{array}$ & \multicolumn{1}{|c|}{ Compound Name } & Solvent & $\begin{array}{c}\text { Extracted } \\
\text { with solvent }\end{array}$ \\
\hline 1 & $\begin{array}{l}\text { Benzene,1,2-dimethoxy-4-( } \\
\text { 2-propenyl) }\end{array}$ & Organic & Ethanol \\
\hline 2 & Shyobunone & Organic & Ethanol \\
\hline 3 & Octadecadienoicacid & Organic & Ethanol \\
\hline 4 & $\beta$ Asarone & Organic & $\begin{array}{l}\text { Ethanol, } \\
\text { Propanol }\end{array}$ \\
\hline 5 & $\begin{array}{l}\text { Tetracyclo(6.2.1.0(3.8)0(3. } \\
\text { amethyl }\end{array}$ & Organic & Ethanol \\
\hline 6 & $\begin{array}{l}\text { Trimethoxyamphetamine,2 } \\
\text { 3,5 }\end{array}$ & Organic & Ethanol \\
\hline 7 & $\begin{array}{l}\text { Pyrimidin-2-one,4-(N-met } \\
\text { hylureido)-1-(4-methylami } \\
\text { nocarbonyloxymethyl) }\end{array}$ & Organic & Ethanol \\
\hline 8 & $\begin{array}{l}\text { 4a,7-Methano-4Ah-naphth( } \\
\text { 1,8a-b)oxirene,octahydro-4 } \\
\text { 4,8,8-tetramethyl }\end{array}$ & Organic & Ethanol \\
\hline 9 & n-Hexadecanoic acid & Organic & Ethanol \\
\hline 10 & Preisocalamendiol & Organic & Propanol \\
\hline 11 & B-ocimene & Organic & Propanol \\
\hline 12 & Methyleugenol & Organic & Propanol \\
\hline 13 & Asarylaldehyde & Organic & Chloroform \\
\hline 14 & Acoramone & Organic & Chloroform \\
\hline 15 & s-cadinol & Organic & Ethanol \\
\hline & & \\
\hline
\end{tabular}

worms and the development of blastema was observed very closely until $8^{\text {th }}$ day of amputation. Worms injected with sterile distilled water had blastema development from $3^{\text {rd }}$ day (Fig 2A) grown gradually on $5^{\text {th }}$ and $8^{\text {th }}$ day (Fig $2 \mathrm{~B}$ and C). Aqueous extract of rhizomes was used as a positive control as it has already been shown to have antimitotic compounds [9]. No growth from amputated region was observed on $3^{\text {rd }}, 5^{\text {th }}$ or $8^{\text {th }}$ day from aqueous extract of rhizomes (Fig 2 D, E and F]. It corresponds well as we reported earlier [9]. Similarly, ethyl acetate fraction injected worms did not develop any blastema on $3^{\text {rd }}, 5^{\text {th }}$ or $8^{\text {th }}$ day (Fig $2 \mathrm{G}, \mathrm{H}$, I). It suggests that compounds that were originally responsible for antimitotic activity in the aqueous extract were partitioned well with ethyl acetate. Generation of blastema was marginally better on $3^{\text {rd }}$ day in worms injected with fractions from ethanol compared to controls (Fig $2 \mathrm{~J}$ ). Growth of blastema was better after $5^{\text {th }}$ day (Fig $2 \mathrm{~K}$ ) and become distinct after 8 days (Fig 2L). It shows that ethanol fraction did not have significant amount of antimitotic compounds. Conversely, this fraction possesses compounds that play significant role in enhancement of cell division, growth or regeneration. The activity of compounds responsible for proliferation might have been suppressed by the presence of antimitotic compounds in aqueous extract. Further analysis on ethanol fraction would reveal the properties of compounds responsible for proliferation. These results clearly suggest that earthworm's regeneration system could be utilized to examine various fractions and narrow down to fewer compounds from the crude extract.

Extraction of A. calamus rhizome powder directly with absolute methanol or ethanol resulted in getting $\alpha$ or $\beta$ asarone compounds $[15,17]$. Many therapeutical properties of this medicinal plant, including anticancer, is attributed toward these two asarones $[18,16]$. Extraction with ethanol and subsequent partition with petroleum ether showed the presence of z-asarone and had insecticidal activity [19]. These data suggest that asarones are highly hydrophobic and getting extracted with organic solvents. Interestingly, ethanol extracts partitioned subsequently with ethyl acetate, which was devoid of $\beta$-asarone, enhanced adipocyte differentiation in 3T3-L1 cells and the identified compound was named as 22-((6-deoxy-a-L-rhamnopyranosyl) oxy)-3,23- [20]. It indicates that compound which has activity towards differentiation of adipose tissue act better when they are devoid of compound like $\beta$-asarone. It corresponds well with our data where aqueous fraction inhibited blastema development, however, the ethanol fraction partitioned from aqueous extract induced cell proliferation. It suggests that compounds that induce proliferation are suppressed by compounds that inhibit cell division. It also depends on the concentration of both compounds available in the extract.

However, when the extract was done with $50 \%$ ethanol, amelioration of nephrotoxicity was found in experiments with mouse [21]. In another report, $50 \%$ ethanol extract showed anti-inflammatory and anti-oxidative response in mouse [22]. These results suggest that rhizome possess many compounds and partitioned differently based on the extraction procedure. Aqueous extract of leaves of $A$. calamus has been shown to have anti-inflammatory activity by using $\mathrm{HaCaT}$ cells [23]. Aqueous extract of rhizomes has also been shown to have wound healing and anti-inflammatory activity in vivo and in vitro respectively [24]. These data strongly suggest that aqueous extract possess wound-healing compounds. Proliferation of cells in amputated worms in ethanol partitioned fractions could be due to the presence of wound healing, anti-inflammatory or anti-oxidative compounds. To identify the compounds which inhibited blastema development, fractions partitioned with ethyl acetate from crude residue obtained from aqueous extract was analyzed in TLC plates with petroleum ether as mobile phase. Two spots having Rf value of 0.03 and 0.06 were found after staining with iodine (Fig 3). Compounds from both spots were scratched off from the Preparative TLC plates and examined for their antimitotic potential using Allium cepa root tips. Many numbers of cells in the root tips were going through different mitotic phases in the samples treated with water. However, the number of mitotic phases were less in samples treated with ethyl acetate fraction. Mitotic index was calculated and found that it significantly reduced in A. cepa root tips that were treated with compounds isolated from TLC compared to control samples [Fig 4] Extraction of rhizomes and leaves of A. calamus with organic solvents and subsequent analysis with TLC has shown to have $\alpha$-asarone and $\beta$-asarone [25]. 


\section{Earthworm, an in Vivo System to Screen Proliferative and Antimitotic Compounds}
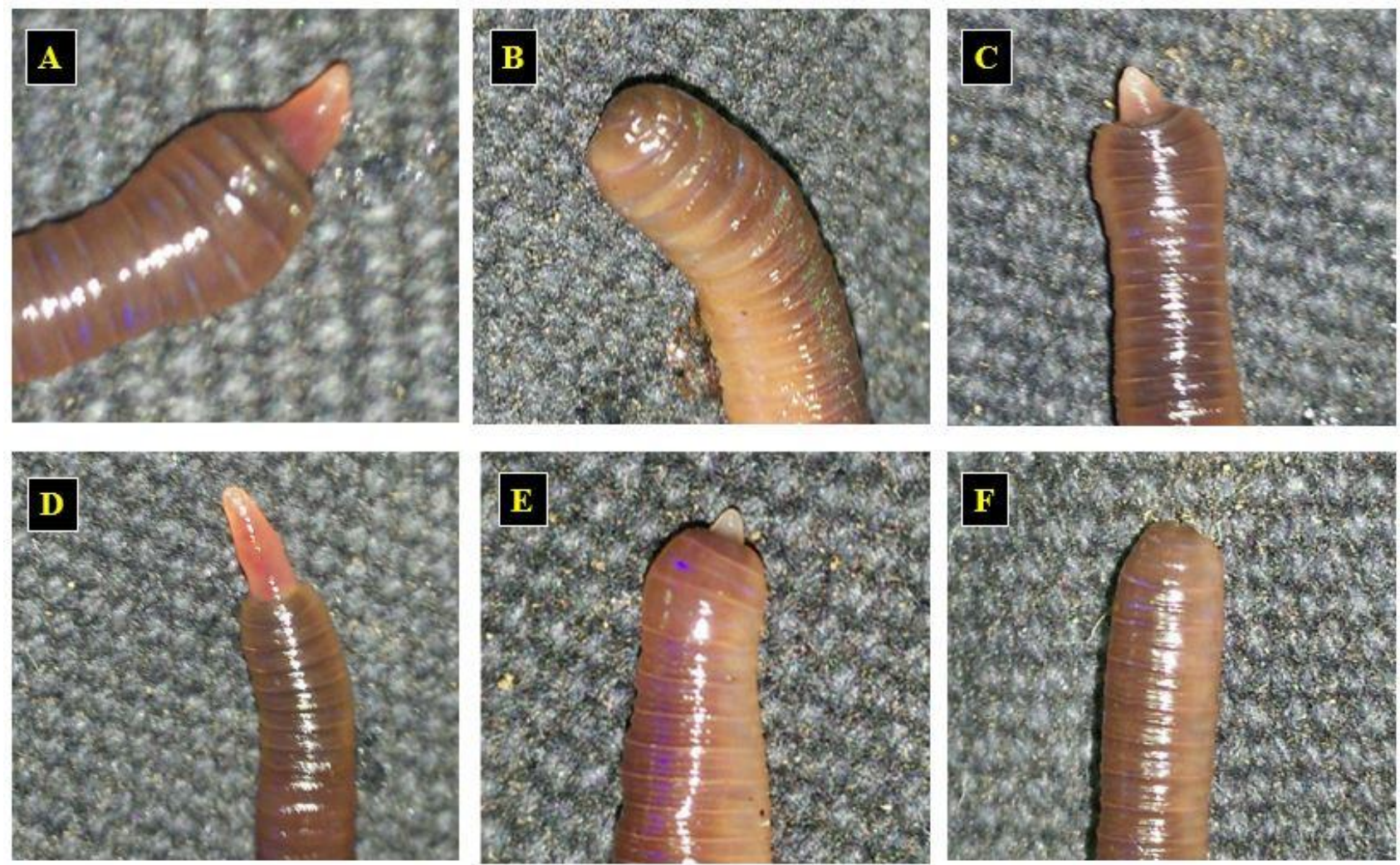

Fig.1 Evaluation of blastema development in E. eugeniae with differential extraction of $A$. calamus.

The worms were injected once in $24 \mathrm{hrs}$ for a period of 8 days with sterile water [A] or the aqueous extract of rhizome partitioned with methanol [B], benzene $[\mathrm{C}]$, ethanol [D], chloroform [E] or ethyl acetate [F]. All photos were taken on $8^{\text {th }}$ day. Blastema development was not seen in worms injected with aqueous extract partitioned with methanol [B] and ethyl acetate $[\mathrm{F}]$. The regeneration of new tissues was found better from extract partitioned with ethanol [D] compared to control [A], benzene [C] or chloroform [E].
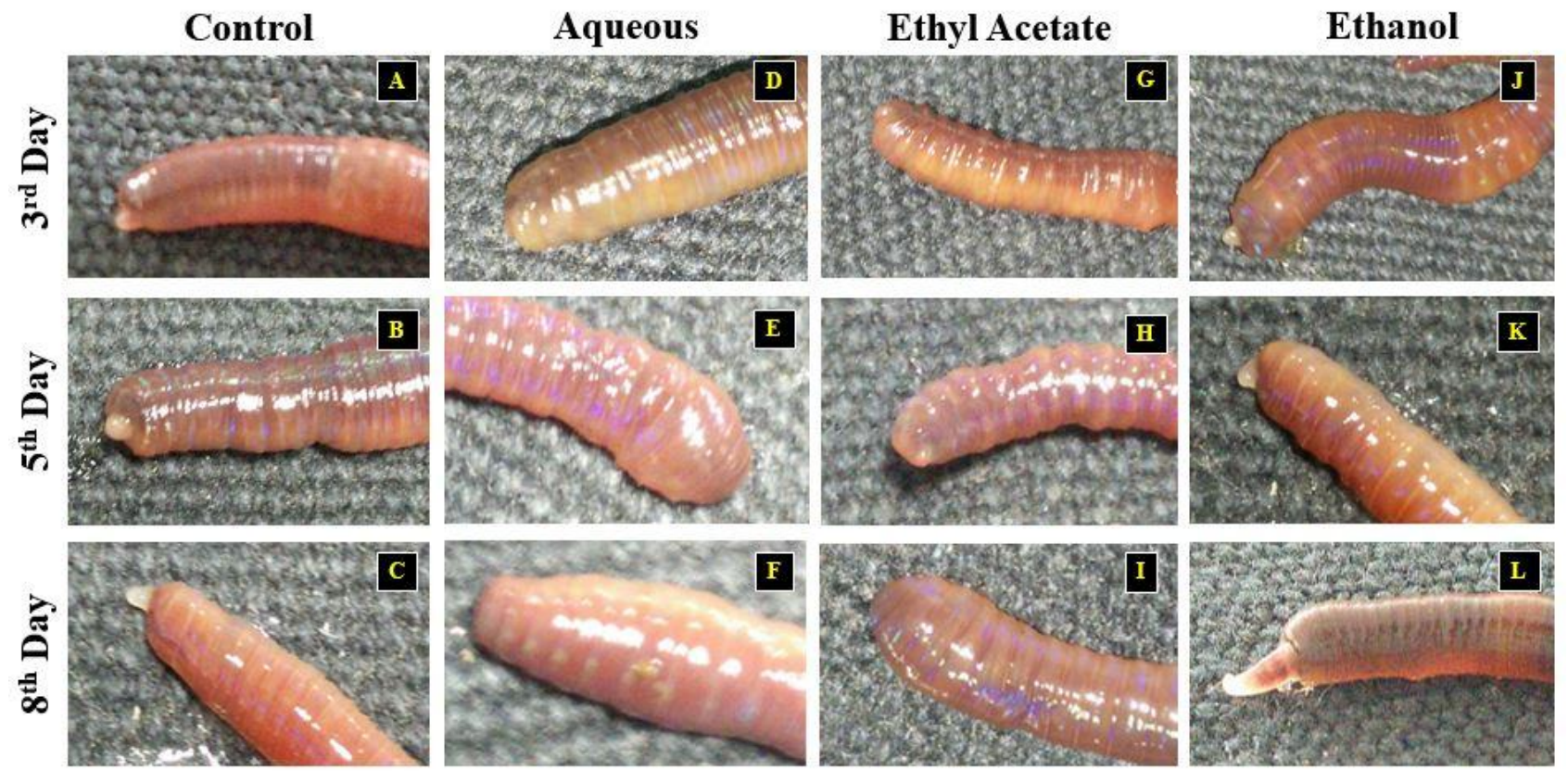

Fig 2. Proliferative and antimitotic compounds from aqueous extract of $A$. calamus.

The control worms were injected with distilled water once in $24 \mathrm{hrs}$ for a period of 8 days and the development of blastema was photographed after $3^{\text {rd }}[\mathrm{A}], 5^{\text {th }}[\mathrm{B}]$ and $8^{\text {th }}$ day $[\mathrm{C}]$. Aqueous extract of A. calamus rhizomes was injected similarly for 8 consecutive days and blastema development was not found after $3^{\text {rd }}[\mathrm{D}], 5^{\text {th }}[\mathrm{E}]$ and $8^{\text {th }}$ day $[\mathrm{F}]$. Ethyl acetate extract partitioned from aqueous extract injected worms did not show any regeneration after 3rd [G], 5th $[\mathrm{H}]$ and $8^{\text {th }}$ day [I]. Ethanol extract partitioned from aqueous extract injected worms showed better proliferation from amputated region after $3^{\text {rd }}[\mathrm{J}], 5^{\text {th }}[\mathrm{K}]$ and $8^{\text {th }}$ day [L].

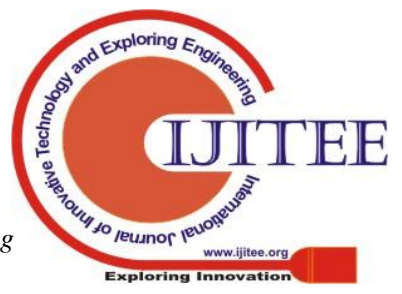




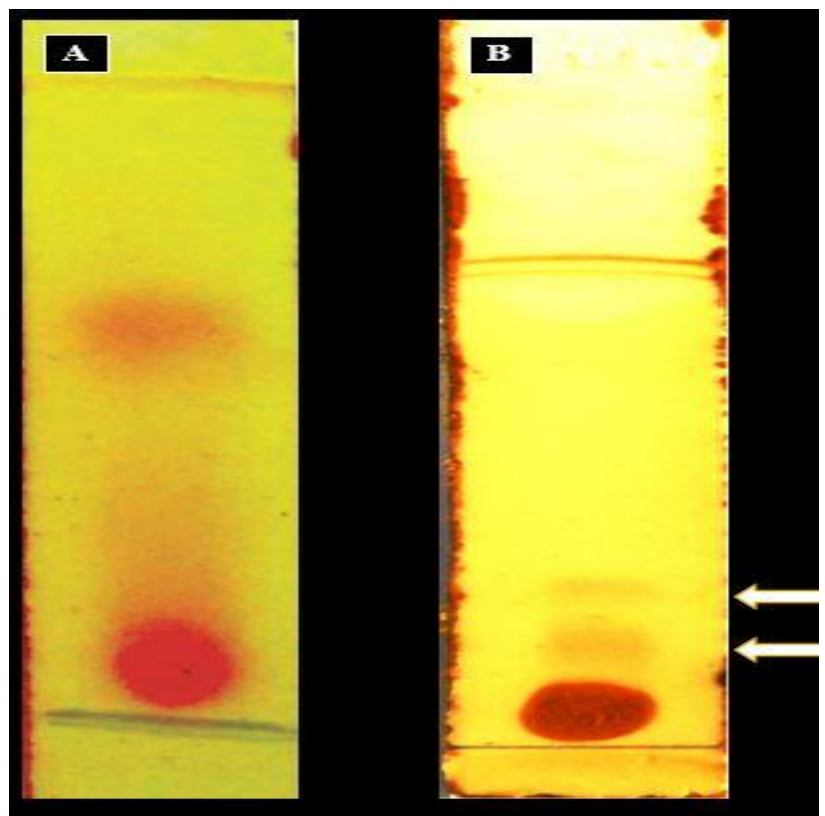

Fig 3. TLC analysis of $A$. calamus extracts.

Aqueous extract of rhizomes [A] or ethyl acetate fraction from aqueous extract [B] were loaded on precoated silica gel plates and mobilized with petroleum ether. Photographs were taken after staining in iodine chamber. Arrows indicate two bands found in sample partitioned with ethyl acetate.

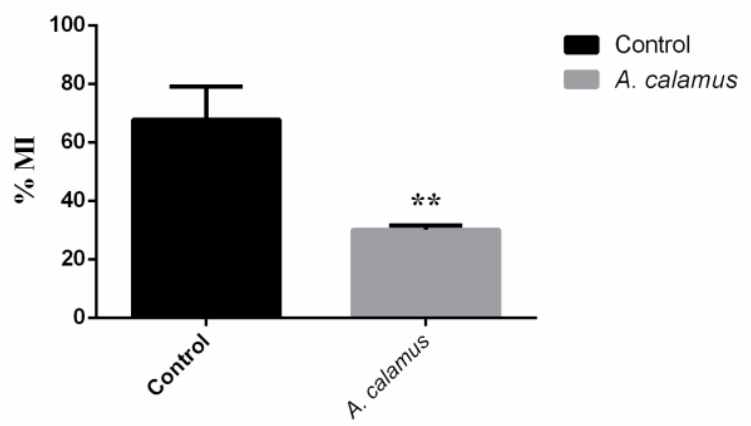

Fig 4. Inhibition of cell division in A. cepa root tips by ethyl acetate fraction.

The graph shows percentage of cells observed in root tips with four phases of mitotic cell division in water-treated control samples or ethyl acetate fraction partitioned from aqueous extract of A. calamus. Mean SEM bar is shown and ** indicates the significant difference.

Hence we extracted the rhizomes initially with sterile water, lipophilic compounds like asarones would have not been extracted. Our results with TLC suggest that fractions partitioned with ethyl acetate possess antimitotic compounds. Further experiments are required to provide more knowledge on these compounds. Interestingly, earthworms' regeneration ability has been utilized recently to study the role of TCTP protein in development of blastema from amputated worms [26]. Taken together, our data strongly suggest that earthworms could be used as a simple in vivo system to identify both antimitotic and proliferative compounds by utilizing their regeneration ability. Similar compounds from any medicinal plant or other sources could be tested by utilizing earthworms.

\section{ACKNOWLEDGMENT}

This research was supported by the Kalasalingam Academy of Research and Education (KARE), deemed to be university, Krishnankoil, Tamil Nadu, India. Mr. C. Rajesh and Mr. R. Prakash are thankful to KARE for receiving the research fellowship.

\section{REFERENCES}

1. B. E. Van Wyk, M.Wink, Medicinal plants of the world [No. Ed. 2], CABI, 2017.

2. A.G. Atanasov, B. Waltenberger, E.M. Pferschy-Wenzig, T. Linder, C Wawrosch, P. Uhrin, V. Temml, L. Wang, S. Schwaiger, E.H. Heiss, J.M. Rollinger, "Discovery and resupply of pharmacologically active plant-derived natural products: A review, ” Biotechnology advances, 2015, 33[8], pp.1582-1614

3. Y. Ren, E.J.C. de Blanco, J.R. Fuchs, D.D. Soejarto, J.E. Burdette, S.M Swanson, A.D. Kinghorn, "Potential Anticancer Agents Characterized from Selected Tropical Plants," Journal of natural products, 2019 , 82[3], pp.657-679.

4. J. Iqbal, B.A. Abbasi, T. Mahmood, S. Kanwal, B. Ali, S.A. Shah, A.T Khalil, "Plant-derived anticancer agents: A green anticancer approach," Asian Pacific Journal of Tropical Biomedicine, 2017, 7[12], pp.1129-1150

5. B.A. Weaver, "How Taxol/paclitaxel kills cancer cells," Mol Biol Cell, 2014, 25: 2677-2681.

6. S.A. Fadeyi, O.O. Fadeyi, A.A. Adejumo, C. Okoro, E.1. Myles, "In vitro anticancer screening of 24 locally used Nigerian medicinal plants,' BMC Complement Altern Med, 2013, 13: 79

7. G.S. Murthy, T.P. Francis, C.R. Singh, H.G. Nagendra, C. Naik, “An assay for screening anti-mitotic activity of herbal extracts," Curr Sci, 2011, 100: 1399-1404.

8. Y. Li, W. Huang, S. Huang, J. Du, C. Huang, "Screening of anticancer agent using zebrafish: comparison with the MTT assay," Biochem Biophys Res Commun, 2012, 422: 85-90.

9. K. Rajamanikkam, S.E. Raja, S.K. Balaji, G.N. Rajavadivu, S Sivasubramaniam, K. Palanichelvam, "Earthworm, a novel in vivo system to validate antimitotic compounds," Turkish Journal of Zoology, 2019, 43[2]:153-63.

10. A. Adan, Y. Kiraz, Y. Baran, "Cell proliferation and cytotoxicity assays," Current pharmaceutical biotechnology, 2016, 17[14], pp.1213-1221.

11. L. Ricci, M. Srivastava, "Wound-induced cell proliferation during animal regeneration," Wiley Interdisciplinary Reviews: Developmental Biology, 2018, 7[5], p.e321.

12. R.M. Kalidas, S.E. Raja, S.A.K.N.M. Mydeen, S.C.J.R. Samuel, S.C.J Durairaj, G.D. Nino, K. Palanichelvam, A. Vaithi, S. Sudhakar, "Conserved lamin A protein expression in differentiated cells in the earthworm Eudrilus eugeniae," Cell biology international, 2015, 39[9], pp.1036-1043.

13. N.G. Daisy, E.R. Subramanian, J.D. Christyraj, D.K. Mani, J.R. Christyraj, K. Ramamoorthy, V. Arumugaswami, S Sivasubramaniam, "Studies on regeneration of central nervous system and social ability of the earthworm Eudrilus eugeniae," Invertebrate Neuroscience, 2016, 1;16[3]:6.

14. A.D. Khwairakpam, Y.D. Damayenti, A. Deka, J. Monisha, N.K. Roy, G. Padmavathi, A.B. Kunnumakkara, "Acorus calamus: a bio-reserve of medicinal values," Journal of basic and clinical physiology and pharmacology, 2018, 29[2], pp.107-122.

15. S. Shailajan, S. Menon, G. Swar, D. Singh, S. Nair, "Estimation and quantitation of $\beta$-asarone from Acorus calamus rhizome and its formulations using validated RP-HPLC method," Pharmaceutical Methods, 2015, 6[2].

16. R. Chellian, V. Pandy, Z. Mohamed, "Pharmacology and toxicology of $\alpha$-and $\beta$-Asarone: A review of preclinical evidence," Phytomedicine, 2017, 32, 41-58. 
17. L.J. McGaw, A.K. Jäger, J. Van Staden, J.N. Eloff, "Isolation of $\beta$-asarone, an antibacterial and anthelmintic compound, from Acorus calamus in South Africa," South African Journal of Botany, 2002, 68[1], 31-35.

18. J. Wu, X.X. Zhang, Q.M. Sun, M. Chen, S.L. Liu, X. Zhang, J.Y. Zhou, $X$. Zou, " $\beta$-asarone inhibits gastric cancer cell proliferation,” Oncology reports, 2015, 34[6], pp.3043-3050.

19. Y. Yao, W. Cai, C. Yang, D. Xue, Y. Huang, "Isolation and characterization of insecticidal activity of [Z]-asarone from Acorus calamus L," Insect Science, 2008, 15[3]:229-36.

20. H.S. Wu, Y.Y. Li, L.J. Weng, C.X. Zhou, Q.J. He, Y.J. Lou, "A Fraction of Acorus calamus L. extract devoid of $\beta$-asarone Enhances adipocyte differentiation in 3T3-L1 cells," Phytotherapy Research: An International Journal Devoted to Pharmacological and Toxicological Evaluation of Natural Product Derivatives, 2007, 21[6]:562-4

21. D. Sandeep, C.K. Krishnan Nair, "Amelioration of cisplatin-induced nephrotoxicity by extracts of Hemidesmus indicus and Acorus calamus," Pharmaceutical biology, 2010, 48[3], pp.290-295.

22. A. Muthuraman, N. Singh, A.S. Jaggi, "Effect of hydroalcoholic extract of Acorus calamus on tibial and sural nerve transection-induced painful neuropathy in rats," Journal of natural medicines, 2011, $1 ; 65[2]: 282-92$.

23. H. Kim, T.H. Han, S.G. Lee, "Anti-inflammatory activity of a water extract of Acorus calamus L. leaves on keratinocyte HaCaT cells," Journal of ethnopharmacology, 2009, 25;122[1]:149-56.

24. G.B. Shi, B. Wang, Q. Wu, T.C. Wang, C.L. Wang, X.H. Sun, W.T. Zong, M. Yan, Q.C. Zhao, Y.F. Chen, W. Zhang, "Evaluation of the wound-healing activity and anti-inflammatory activity of aqueous extracts from Acorus calamus L," Pak J Pharm Sci, 2014, 1;27[1]:91-5.

25. S.A. Devi, D. Ganjewala, "Antimicrobial activity of Acorus calamus [L.] rhizome and leaf extract," Acta biologica szegediensis, 2009, $1 ; 53[1]: 45-9$.

26. E.R. Subramanian, N.G. Daisy, D.K. Sudalaimani, K. Ramamoorthy, S. Balakrishnan, J.D.S. Christyraj, V. Arumugaswami, S. Sivasubramaniam, "Function of translationally controlled tumor protein [TCTP] in Eudrilus eugeniae regeneration," PLoS One, 2017, 12: $\mathrm{e} 0175319$.

\section{AUTHORS PROFILE}

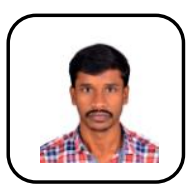

Kamaraj Rajamanikkam studied M.Tech Biotechnology from Kalasalingam University, Tamil Nadu, India. Currently he is working as research fellow in Dr. Reddy's Institute of Life Sciences (DRILS), Hyderabad, India.

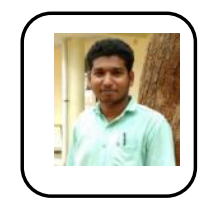

Chandran Rajesh has completed his M. Sc Biotechnology in Madurai, Tamil Nadu, India. Currently he has been enrolled in $\mathrm{PhD}$ program in department of Biotechnology in Kalasalingam University.

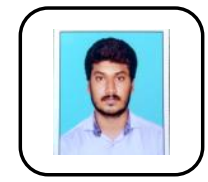

Ramesh Prakash born in Karur, Tamilnadu in 1991. He received his M.Phil degree from the Bharathidasan University, Trichy, in 2015 and obtained his MSc degree in 2014 at St. Joseph's College, Trichy. He joined PhD in 2015 under the supervision of Dr. Narayanan Selvapalam at Kalasalingam Academy of Research and Education in Virudhunagar district. He is awarded a direct-Senior Research Fellowship from CSIR in 2018 to till date. His research interest is on the area of nanomaterials synthesis and supramolecular chemistry. 